\title{
Chapter 8 \\ Conclusion: Long Term Prospects and Global Health Collaboration
}

\author{
Nicole Webster
}

\subsection{Introduction}

The general direction of global health within academia seems to have moved to a stage where easily accessing information is vital to notions of transparency and interactions. The task of universities is to find and create pathways that inform society and our students about the realities of health across various nation states. While this might seem like a daunting task, the structure of Pan Institution Network for Global Health (PINGH) has provided avenues for exploring and addressing complex and interrelated health issues among global partners within an academic setting.

This book provides a platform for unpacking both the success and challenges faced by individuals in the academy (students, faculty, and administrators) and the communities in which they work in the world of global health. Published chapters reveal a collection and dissemination of performance, networks, systems, and people that contribute to the PINGH network and its goals. PINGH in its rawest form is a moving collection of parts and people working to achieve the goal of formalizing a network that enables local and national actors to address some of the world's most pressing health issues. In coordination with local agencies, hospitals, universities, and other key individuals, the network provides a type of methodology for engagement and problem-solving. In addition to hands-on engagement and experiences, the PINGH network serves as a space for nurturing and developing ideas. The network provides a domain for those who wish to test ideas or brings together like minds to address global health issues, while also creating pathways to the inclusion of diverse individuals, sectors of society, and communities in this complex and fast-paced field.

\footnotetext{
N. Webster $(\bowtie)$

Department of Agricultural Economics, Sociology, and Education,

Pennsylvania State University, State College, PA, USA

e-mail: nsw10@psu.edu 
Another outcome of the chapters and primarily a result of the PINGH structure is an opportunity to advance the focus of global health collaborations and research with students and community partners. One might argue that this type of research already exists within other health-related organizations; however, the types of conversations, projects, and research carried out within PINGH highlight the impact that can happen when the community works with students in the co-creation of the knowledge and research. Take for example the Project Redemption project from Chap. 6, which highlights what can happen when communities that have often been overlooked are included as contributing participants and central to the core theme of the study. In other chapters (see Chaps. 4 or 7), the inclusion of undergraduate and graduate students was purposeful and impactful to not only the students but also provided useful information on potential changes that could ultimately influence how to better integrate students into other programmatic roles of these global health programs.

Furthermore, book chapters reveal challenges when working with global partners such as access and transparency of national data or access to other pertinent information. Despite these issues, authors recognized through these types of global health projects, greater awareness and policies (both PINGH and national/regional country policies) could be developed to address some of these limitations that impact programs. Another important issue raised across most chapters was the significance of a robust program design. When programs are strategically developed to include students (graduate and undergraduate), develop and challenge learning, incorporate community voice, and acknowledge critical reflection, there is an opportunity to change the status quo of student learning in global contexts. These components contribute to a learning environment that provides the student and the community with an opportunity to contribute to the learning process and ultimately create an experience that is meaningful to all.

In reviewing the system of PINGH and its goals, there were three common themes found in all the chapters. Projects and activities highlighted the elements of a network that values (1) community voice and inclusivity, (2) student engagement and contributions, and (3) faculty and site collaboration.

\subsection{Community Voice and Inclusivity}

Community participation in health care is vital and integral to the approaches and integration of the project. Community participation gives individuals a sense of being a part of the process and assisting in the development of research and or policies that will ultimately impact their health and livelihoods. As evidenced by the inclusion of the center director in the waste picker project or the community members in the diabetes research; the community was an integral part of the project, whether the authors noted successes or breakdowns in the process. What was consistent was the need to include the community as valued members of the process and 
not just program participants. Strategies to achieve healthy communities have viewed the inclusion of individuals such as community case managers or community health workers as critical components. The inclusion of the community in the case of these PINGH projects responded to community-level treatment and interventions for pressing issues that impact the community as a whole. As a result, activities focused on crucial essential elements necessary for including strategic community members (i.e. organizations, people, institutions), that would enable the implementation of the research or project. Attributes incorporated in PINGH projects which assisted in fostering community participation included the following:

- Contributing — community contributes time, expertise, and resources

- Consulting - community is asked for their views and knowledge

- Managing - community participates in making decisions and provides input

Although each PINGH project did not incorporate each of the three components mentioned above, they all displayed aspects of each element at specific points of time during the project. And while authors noted to hints of tension when working with the community, they expressed the desire and willingness in working with the community in a participatory manner.

Participatory and community processes are developed through the construction of trusting and collaborative relationships among all stakeholders, through inclusive actions. The relational work - sometimes mediating between different options or positions and in case of possible conflicts - is, therefore, a continuous and fundamental element. Construction and conduction of moments and meeting spaces and collaboration for the development of these initiatives, with the participation of citizens and technical-professional resources assisted in fostering program models that could be scaled up and replicated. Permanent listening and participatory research for a better and broader knowledge of the health conditions of the site areas led to more informed citizens and provided more significant information and socialization of community knowledge about health.

A review of the different interpretations of community participation shows a continuum that goes from the cooperative mode where the community provides information and manpower to more active and creative forms of participation in decision-making, negotiation, and presentation of proposals and co-administration of the resources. A vital aspect of these projects was the capacity and training built into the plans that facilitated participation by higher numbers of the community, leading to projects that have the potential for a sustainable future.

\subsection{Student Engagement and Contributions}

In the past decade, within higher education, there has been a growing conversation on the role and impact of students engaged in relevant and meaningful course content. Researchers have illustrated that student engagement is the most significant 
Table 8.1 Engaged student learning

\begin{tabular}{l|l}
\hline $\begin{array}{l}\text { Meaningful and relevant } \\
\text { program content }\end{array}$ & $\begin{array}{l}\text { Students introduced to activities they believed as being useful } \\
\text { and relevant to current academic program and future career goals }\end{array}$ \\
\hline $\begin{array}{l}\text { Fosters a sense of } \\
\text { competence }\end{array}$ & $\begin{array}{l}\text { Students are given opportunities to evaluate their personal } \\
\text { growth and learning }\end{array}$ \\
\hline $\begin{array}{l}\text { Embraces collaborative } \\
\text { learning }\end{array}$ & $\begin{array}{l}\text { Activities enabled students to work with peers and } \\
\text { community-Amplifying a sense of connection to others }\end{array}$ \\
\hline $\begin{array}{l}\text { Promotes mastery orientation } \\
\text { or exposure }\end{array}$ & $\begin{array}{l}\text { Student activities introduced them to new concepts/communities/ } \\
\text { activities or allowed them to develop further skills learned in } \\
\text { classroom settings }\end{array}$ \\
\hline
\end{tabular}

predictor of retention and cognitive and personal development in college students (Belcheir 2000; Bridges et al. 2001; Nelson Laird et al. 2004; Kuh 2007). Studies also show that specific pedagogical practices are associated with higher levels of student engagement (Deakin Crick and Goldspink 2014). Student's engagement in society, their associations and networks, and the characteristics of their communities profoundly affect their outlook on life. The attributes commonly found in courses which engage youth in learning outside the classroom and in a global context incorporate some characteristics-structured participation; engagement with community organizations; connectedness with neighborhoods; and relationships with government and groups unlike one's own. Combined, they often contribute to positive learning outcomes and a deeper understanding of the systems and underlying history that adds to the health issues being studied.

Expanding this notion of engagement within the healthcare sector was most evident in many of the chapters. Authors discussed the multifaceted role of students in the projects, such as research associates, data organizers and collectors, and coauthors of research articles. In many cases, the students were engaging in work beyond what is typically carried out in engagement activities and even more so within the classroom. Students were exposed to research and projects that fostered conversations with organizations and community members who were able to provide context and meaning beyond a textbook. Moreover, students were assigned roles and responsibilities which could lead to personal growth and development.

In reviewing chapters which were intentional in the inclusion of students, both graduate, and undergraduates, each incorporated essential elements central to student engagement. Each project was mindful in the design and structure of the activity which led to students gaining greater knowledge of global health issues, exposure to various actors and determinants of health issues, and open dialogue and conversations with health professionals and others central to local and global advancements in global health. The intentionality in which each project approached the inclusion of students resulted in other components of engaged student learning (see Table 8.1).

Students' knowledge of the realities of global health was enhanced by their participation in the noted projects and further support the value of PINGH which provides support systems within colleges and units to foster this type of student learning. 


\subsection{Faculty and Site Collaboration: Fostering North-South Collaborations}

Recognizing the value of understanding the interconnectedness and interactions of global health, the PINGH structure facilitates approaches for developing and fostering institutional relationships and collaborative research agendas. Although most projects were developed within the context of a PINGH meeting, they all expanded to reach out to global partners who may or may not have been at meetings. The goal is to create a project or research agenda that focused on an idea or universal health need. Conversations which formed the basis of these projects seemed to be done with the disposition of including multiple voices and perspectives. Participants and organizers approached their project with a sense of urgency and an understanding of their potential role in creating awareness of challenges that exist within areas of global health such as data collection methods, transparency of data, or improving the understanding in an evidence based material. Additional features of these projects leaned towards the role and importance of faculty in fostering global educational experiences for students, challenging the status quo of student learning beyond the traditional Western models of thinking and learning, and developing bilateral partnerships between students and emerging and experienced faculty.

The framework of PINGH enabled faculty and staff to consider conceptual frameworks that pressed learning environments to take place in both the Global North and South. Feasibility and specifications of learning sites and the relationship between these sites and selected social and global health trends aided in fostering these relations between countries. The inclusion of the north-south connection was not without challenges such as language barriers or understanding of cultural values and norms that impacted healthcare systems. But at the very least, participants were exposed to a different way of being and were able to co-construct knowledge with a diverse set of colleagues who held different sets of ideologies and systems.

The merit of these relationships was due to actions and behaviors that supported the engagement of individuals across and within various institutions and countries. Most notable were:

1. Conferences and workshops within multiple settings (US and abroad)

(a) Discussion of ideas and potential projects took place in these settings

(b) Training of emerging researchers and fostering support for all participants

(c) Networking opportunities

2. Facilitation of small pilot grants to support projects/research

(a) Enabled groups to continue noted work discussed at workshops/conferences

3. Transparent communication strategies

(a) Newsletters, Skype calls

4. Interdisciplinary approach to project ideas

(a) Several institutions part of a project 


\subsection{PINGH Network Structure and Recommendations}

PINGH serves as a system which facilitates the fostering of ideas and advocates for activities related to global health. The success of the network clearly rests in the hands of all participants as well as the leadership. It is clear from the chapters that each project had a clear focus and goal that contributed to the success and helped to reveal potential areas of growth for PINGH members. As an organization designed to support multiple partners, it is clear that the structure encourages bilateral and multilateral programming to bring about informative and transformative changes to students, professionals, and most importantly to the global health community (see Fig. 8.1).

When examining the overarching structure and role of PINGH, it is an organization that can fill multiple gaps in the academia and the global health network. By providing educators, students, and the community with a framework, PINGH places value on the role of global health. A structure that supports ideas fosters collaboration and stimulates new avenues for existing, and emerging scholars situates the complexity of global health and the importance of cooperation and connectedness in addressing some of life's most challenging health issues. In light of this, what follow are a series of recommendations to continue to strengthen the existing partnerships of PINGH and develop more sustainable long term collaboration:

- For data collection and collaborative efforts with multiple partners, a multipronged strategy should be pursued in which large-scale surveys could be conducted by several institutions, providing greater opportunities for students, agencies, and the community at large. The greatest promise lies in research that has a longitudinal structure and includes avenues for exploring resources ranging from regional data to national data that are amenable to community-level analyses.

- Due to the importance of enhancing students' learning and advancement, greater avenues should be created to include students in the inclusion of projects to enhance both technical and leadership skills. Based on the projects that included students, there should be greater structures put in place to support their academic and research development further supporting them with experiences that have value beyond the classroom.

- The PINGH network should establish a technical team that assists the leadership team in further highlighting the global health research efforts. A technical team

\begin{tabular}{|c|c|c|}
\hline ENGAGING & ENRICHING & CULMINATE \\
\hline $\begin{array}{l}\text { Participating in a } \\
\text { class/program in } \\
\text { research through } \\
\text { engaged learning }\end{array}$ & $\begin{array}{l}\text { Moving from self to } \\
\text { community and } \\
\text { global perspectives } \\
\text { - Research } \\
\text { - Study Abroad } \\
\text { - Internship } \\
\text { - Leadership }\end{array}$ & $\begin{array}{l}\text { In-depth, integrated } \\
\text { focus on ways of knowing } \\
\text { related to the discipline. } \\
\text { - Extends the field } \\
\text { - Critiques the field } \\
\text { - Applies knowledge in } \\
\text { the field }\end{array}$ \\
\hline
\end{tabular}

Fig. 8.1 PINGH network 
could be led by graduate students, further fostering their social and technical skills and assisting them in building their networks of colleagues. This team could create strategies to promote research and other work being conducted through social media and other platforms to help develop a stronger tie between all the institutions.

- For fostering and monitoring relationships between emerging and seasoned researchers, an online platform could be developed to support these relationships. This component could assist in creating a system where content and resources are shared, and more importantly, housed for future reference. The platform may be especially helpful in moving forward creative and innovative ideas about types of research and opportunities that offer the most promise.

- In mapping the way forward for growing and managing partners, the PINGH network might consider a strategy for developing the necessary capabilities for a rotating leadership team. With a rotating system, institutions will be able to not only take the lead in guiding the organization but also take a pivotal role in guiding conversations and agendas that foster a diverse set of global health partnerships and research.

\section{References}

Belcheir MJ (2000) The National Survey of Student Engagement: results from Boise State freshmen and seniors. (Report No. BSU-RR-2000-04). Office of Institutional Advancement (ERIC Document Reproduction Service No. ED480914), Boise

Bridges BK, Kuh GD, O'Day P (2001) The National Survey of Student Engagement. https://www. naspa.org/. Accessed 27 Nov 2017

Deakin Crick R, Goldspink C (2014) Learner dispositions, self-theories and student engagement. Br J Educ Stud 62(1):19-35. https://doi.org/10.1080/00071005.2014.904038

Kuh GD (2007) What student engagement data tell us about college readiness. Peer Rev 9(1):4

Nelson Laird TF, Bridges BK, Morelon-Quainoo CL et al (2004) African American and Hispanic student engagement at minority serving and predominantly white institutions. J Coll Stud Dev 48(1):39-56. https://doi.org/10.1353/csd.2007.0005

Open Access This chapter is licensed under the terms of the Creative Commons Attribution 4.0 International License (http://creativecommons.org/licenses/by/4.0/), which permits use, sharing, adaptation, distribution and reproduction in any medium or format, as long as you give appropriate credit to the original author(s) and the source, provide a link to the Creative Commons license and indicate if changes were made.

The images or other third party material in this chapter are included in the chapter's Creative Commons license, unless indicated otherwise in a credit line to the material. If material is not included in the chapter's Creative Commons license and your intended use is not permitted by statutory regulation or exceeds the permitted use, you will need to obtain permission directly from the copyright holder.

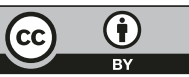

